\title{
BMJ Open Methotrexate and prednisolone study in erythema nodosum leprosum (MaPs in ENL) protocol: a double-blind randomised clinical trial
}

\author{
Barbara de Barros (D) , ${ }^{1}$ Saba M Lambert (D) , ${ }^{1,2}$ Mahesh Shah, ${ }^{3}$ Vivek V Pai, ${ }^{4}$ \\ Joydeepa Darlong, ${ }^{5}$ Benjamin Jewel Rozario, ${ }^{6}$ Medhi Denisa Alinda, ${ }^{7}$ \\ Anna M Sales, ${ }^{8}$ Shimelis Doni, ${ }^{2}$ Deanna A Hagge, ${ }^{3}$ Dilip Shrestha, ${ }^{3}$ \\ M. Yulianto Listiawan, ${ }^{7}$ Abeba M Yitaye, ${ }^{2}$ Jose A C Nery, ${ }^{8}$ Kapil D Neupane, ${ }^{3}$ \\ Vivianne L A Dias, ${ }^{8}$ C. Ruth Butlin, ${ }^{6}$ Peter G Nicholls, ${ }^{1}$ Diana Lockwood, ${ }^{1}$ \\ Stephen L Walker (D) ${ }^{1}$
}

To cite: de Barros B, Lambert SM, Shah M, et al. Methotrexate and prednisolone study in erythema nodosum leprosum (MaPs in ENL) protocol: a double-blind randomised clinical trial. BMJ Open 2020;10:e037700. doi:10.1136/ bmjopen-2020-037700

- Additional material is published online only. To view please visit the journal online (http://dx.doi.org/10.1136/ bmjopen-2020-037700)

Received 13 February 2020 Revised 07 October 2020 Accepted 23 October 2020

Check for updates

(c) Author(s) (or their employer(s)) 2020. Re-use permitted under CC BY-NC. No commercial re-use. See rights and permissions. Published by BMJ.

For numbered affiliations see end of article.

Correspondence to

Dr Barbara de Barros;

barbara.de-barros@|shtm.ac.uk

\begin{abstract}
Introduction Erythema nodosum leprosum (ENL) is an immunological complication of leprosy. ENL results in morbidity and disability and if it is not treated can lead to death. The current treatment consists of thalidomide or high doses of oral corticosteroids for prolonged periods. Thalidomide is not available in many leprosy endemic countries. The use of corticosteroids is associated with morbidity and mortality. Identifying treatment regimens that reduce the use of corticosteroids in ENL is essential. Methotrexate (MTX) is used to treat many inflammatory diseases and has been used successfully to treat patients with ENL not controlled by other drugs, including prednisolone and thalidomide. We present the protocol of

\section{Strengths and limitations of this study}

- This is the first randomised controlled trial to evaluate efficacy of methotrexate (MTX) in the management of erythema nodosum leprosum (ENL).

- We will use the Erythema Nodosum Leprosum International STudy ENL Severity Scale to evaluate the severity of ENL to ensure consistency of patient recruitment between the study centres.

- Participants will be stratified according to the type of ENL acute or chronic and recurrent.

- Data will be collected on adverse events.

- MTX can cause severe nausea, which may lead to loss of allocation concealment.
\end{abstract} the 'MTX and prednisolone study in ENL' (MaPs in ENL) a randomised controlled trial (RCT) designed to test the efficacy of MTX in the management of ENL.

Methods and analysis MaPs in ENL is an international multicentre RCT, which will be conducted in leprosy referral centres in Bangladesh, Brazil, Ethiopia, India, Indonesia and Nepal. Patients diagnosed with ENL who consent to participate will be randomly allocated to receive 48 weeks of weekly oral MTX plus 20 weeks of prednisolone or 48 weeks of placebo plus 20 weeks of prednisolone. Participants will be stratified by type of ENL into those with acute ENL and those with chronic and recurrent ENL. The primary objective is to determine whether MTX reduces the requirement for additional prednisolone. Patients' reported outcome measures will be used to assess the efficacy of MTX. Participants will be closely monitored for adverse events.

Ethics and dissemination Results will be submitted for publication in peer-reviewed journals. Ethical approval was obtained from the Observational/Interventions Research Ethics Committee of the London School of Hygiene \& Tropical Medicine (15762); The Leprosy Mission International Bangladesh Institutional Research Board (in process); AHRI-ALERT Ethical Review Committee, Ethiopia; Ethics Committee of the Managing Committee of the Bombay Leprosy Project; and The Leprosy Mission Trust India Ethics Committee; the Nepal Health and
Research Council and Health Research Ethics Committee Dr. Soetomo, Indonesia. This study is registered at www. clinicaltrials.gov. This is the first RCT of MTX for ENL and will contribute to the evidence for the management of ENL. Trial registration number NCT 03775460 .

\section{INTRODUCTION}

Erythema nodosum leprosum (ENL) is an immunological complication of borderline lepromatous (BL) leprosy and lepromatous leprosy (LL). ${ }^{1}$ ENL affects up to $50 \%$ of individuals with LL and approximately 5\%-10\% of patients with BL. ${ }^{12}$ It is estimated that over 50000 new patients with leprosy diagnosed each year are at risk developing of ENL, ${ }^{3}$ which may occur before, during or after successful completion of multidrug therapy (MDT). The inflammatory state of ENL causes significant morbidity and may be associated with death. ${ }^{34}$ Having a family member with ENL may produce severe economic hardship. ${ }^{5}$ 
ENL is a multisystem inflammatory disorder characterised by extensive crops of painful skin lesions, fever, arthralgia, arthritis, osteitis, dactylitis, lymphadenitis, iritis, orchitis and neuritis. When severe, lesions may ulcerate. ENL is often chronic requiring treatment for several years. ${ }^{1}$

The histology of ENL skin lesions classically shows an intense perivascular infiltrate of neutrophils throughout the dermis and subcutis. ${ }^{6}$ There is evidence of neutrophils and immune complexes playing a role in the inflammation associated with ENL, yet it is uncertain whether they initiate the process. ${ }^{7}$ There is also evidence of $\mathrm{T}$ lymphocyte and macrophage activation and expression of mRNA for Tumor Necrosis Factor- $\alpha$ (TNF $\alpha$ ) and IL-12 in the skin. ${ }^{8}$ Several studies have shown increased levels of TNF $\alpha$, IL-6, IL-12 and IL-17, in skin and blood. ${ }^{79} 10$

Patients with ENL are treated with corticosteroids and/ or thalidomide, which are used for prolonged periods of months or even years. ${ }^{4}$ Thalidomide is effective for many individuals with ENL but is not readily available in many countries because of its teratogenic effects. ${ }^{11} 12$ Thalidomide is also associated with adverse effects such as somnolence, nausea, neurotoxicity, dizziness and thromboembolism, which may limit its use. ${ }^{13}$ Many patients require prolonged, high doses of corticosteroids to control their inflammation that are associated with morbidity and in some settings death. ${ }^{3}$

The identification of other agents for controlling ENL is a priority. ${ }^{14}$ Since the introduction of MDT, there have been eight randomised controlled trials (RCTs) of potential treatments for ENL, involving just 369 (median 22 (range 10-100)) individuals and all had significant methodological limitations including lack of standardisation, allocation concealment and non-validated outcome measures. ${ }^{15-22}$

\section{Rationale for using methotrexate}

Methotrexate (MTX) is an immunosuppressant agent used in the treatment of malignant and inflammatory diseases. ${ }^{23}{ }^{24}$ MTX was first introduced in 1948 to treat acute leukaemia and in 1951, Gubner published his findings on the rapid improvement of psoriasis in patients being treated with aminopterin, an unstable precursor of MTX. ${ }^{25}$ Low doses of oral MTX are widely used in paediatric and adult care to manage TNF- $\alpha$-driven autoimmune and inflammatory diseases including psoriasis, inflammatory spondylo-arthritides, vasculitis and inflammatory bowel disease, in doses between $7.5 \mathrm{mg}$ and $25 \mathrm{mg}$ once a week. ${ }^{26}$ MTX is included in the WHO model list of essential medicines. ${ }^{27}$

The mechanisms by which low-dose oral MTX exerts its clinical effects are not fully understood. However, there is evidence of action on proinflammatory cytokines such as TNF- $\alpha$, IL-1, IL-6 and immune-regulation pathways. ${ }^{28}$

Dermatologists and leprologists are familiar with using MTX, which is widely available and affordable in comparison to other agents used to manage ENL. There are reports, including a case series of MTX having a beneficial effect in the management of ENL, ${ }^{29-31}$ however, there are no controlled trials of MTX in ENL.

MTX may take up to 12 weeks for a therapeutic effect to be noticeable in psoriasis. ${ }^{24}$ We hypothesise that MTX used in conjunction with prednisolone will improve the clinical outcomes for patients with ENL.

\section{METHODS AND ANALYSIS \\ Definitions}

ENL is defined as occurring when an individual with BL or LL leprosy develops 10 or more tender papular and/ or nodular skin lesions.

Three clinical patterns of ENL are described: single acute episodes, recurrent episodes and chronic. ${ }^{1320}$

Acute ENL is defined as occurring if a patient has either a first episode of ENL of less than 24 weeks duration or experiences a second or subsequent episode of ENL, which lasts less than 24 weeks and occurs 84 days (ie, 12 weeks) or more after stopping treatment for ENL. ${ }^{4}$

Chronic ENL is defined as occurring for more than 24 weeks during which a patient has required ENL treatment either continuously or where any treatment-free period is 27 days or less. ${ }^{4}$

Recurrent ENL is defined as occurring if a patient experienced a second or subsequent episode of ENL occurring between 28 and 84 days after stopping treatment for ENL. ${ }^{4}$

Erythema Nodosum Leprosum International STudy (ENLIST) ENL severity scale (EESS) is a 10-item validated severity scale which will be used as an outcome measurement.

\section{Study design}

MTX and prednisolone study in ENL (MaPs) is a multicentre double-blind RCT with two treatment arms, to study the efficacy of MTX and prednisolone in ENL compared with prednisolone and placebo. Participants will be stratified by type of ENL (acute or chronic/recurrent). The procedures for both types will be the same, however, they will be analysed separately.

Specialist leprosy referral institutions from six countries will participate in this study: DBLM Hospital Nilphamari; The Leprosy Mission Bangladesh; Oswaldo Cruz Institute; Rio de Janeiro, Brazil; the ALERT Center, Addis Ababa, Ethiopia; The Leprosy Mission Trust India, New Delhi, India; Bombay Leprosy Project, Mumbai, India; Dr Soetomo Hospital, Surabaya, Indonesia and Anandaban Hospital; The Leprosy Mission Nepal, Nepal.

\section{Participants}

Participants will be the patients with leprosy diagnosed with ENL between 18 and 60 years of age, who give informed consent (online supplemental appendix 1, page 47). Participants must have an ENLIST EESS of 9 or more. EESS is a 10-item clinical severity scale for ENL, which has been developed and validated by the ENLIST group. ${ }^{32}$ The range of scores possible is $0-30$ and a score 
of 9 or more has been shown to be associated with more severe ENL. Participants must also have at least 10 cutaneous ENL lesions.

Patients with longstanding ENL of more than 4 years, pregnant and breastfeeding women, patients coinfected with hepatitis B or C or HIV, tuberculosis, pulmonary fibrosis and individuals with contra-indications to MTX will be excluded. Male and female patients not willing to practise contraception for the duration of the study will be excluded (in view of the teratogenic potential of MTX). Inclusion and exclusion criteria are listed in online supplemental appendix 2.

\section{Outcomes}

- Primary outcomes

The primary outcomes of interest are the proportion of individuals who have not required additional prednisolone during the first 24 weeks and the first 48 weeks. These measurements were chosen because the requirement for additional prednisolone is an objective marker of ENL relapse and treatment failure.

- Secondary outcomes

The secondary outcomes to be assessed by comparisons between treatment arms are as follows. (1) The proportion of individuals with adverse events (AEs), (2) the proportion of individuals who do not require prednisolone at 60 weeks, (3) the number of flares of ENL per individual requiring additional prednisolone up to 60 weeks, (4) the maximal severity of flares of ENL requiring additional prednisolone up to 60 weeks, (5) the change in EESS score from baseline to the first flare of ENL requiring additional prednisolone, (6) the proportion of individuals who have not required additional prednisolone in the 60 weeks of the trial. (7, 8 and 9) The changes in patient-reported health-related quality of life (HRQoL) at 24, 48 and 60 weeks.

Participants will be assessed clinically and with investigations including a full blood count, renal function and liver function tests. Validated local language versions of the Dermatology Life Quality Index and the 36-item Short Form Survey will be used to assess HRQoL.

\section{Randomisation and allocation concealment}

Each drug pack is identified by a serial number and the contents determined by a process of block randomisation that ensures an equal number of active and placebo treatments within each block.

Drug packs are to be distributed to centres in a way that maintains the serial numbering, so there will be only minor differences in the number of active and placebo drug packs available in each centre. In each centre, the drug packs are to be distributed in order by serial number. The key will be held by the Principal Investigator (PI), study manager and local PI of each centre and will be broken after the data analysis is completed or earlier for patients with severe AEs as defined by the protocol.

\section{Sample size calculation}

In participants with acute ENL, if MTX reduces recurrence requiring additional steroid treatment by $30 \%$ (ie, ENL recurs in $37 \%$ rather $67 \%$ as in the published study by Kaur $e t a l^{18}$ ) then for a $90 \%$ power with $\alpha=0.05$, the number of participants required in each arm of this RCT is 57. Assuming 20\% loss to follow-up, we require 142 participants.

In participants with chronic or recurrent ENL, if the proportion of patients taking $50 \%$ less prednisolone by the end of the study is increased with MTX treatment by $20 \%$ (assuming that $40 \%$ of those in the MTX group will achieve this target and 20\% taking prednisolone will achieve this target, that is, two times the proportion in the MTX arm) then for $90 \%$ power with $\alpha=0.05$, the number of participants required in each arm of this RCT is 109 . Assuming $20 \%$ loss of follow-up, we would require 274 participants with chronic/recurrent ENL.

\section{Follow-up}

Participants will be in the study for 60 weeks and will be reviewed on 20 occasions. Participants who miss follow-up appointments will be contacted by phone.

The overview of the study is shown in figure 1 .

\section{Treatment arms}

All participants in the intervention arm will receive an initial dose of oral MTX $10 \mathrm{mg}$, which will be increased to $15 \mathrm{mg}$ the following week. Participants weighing less
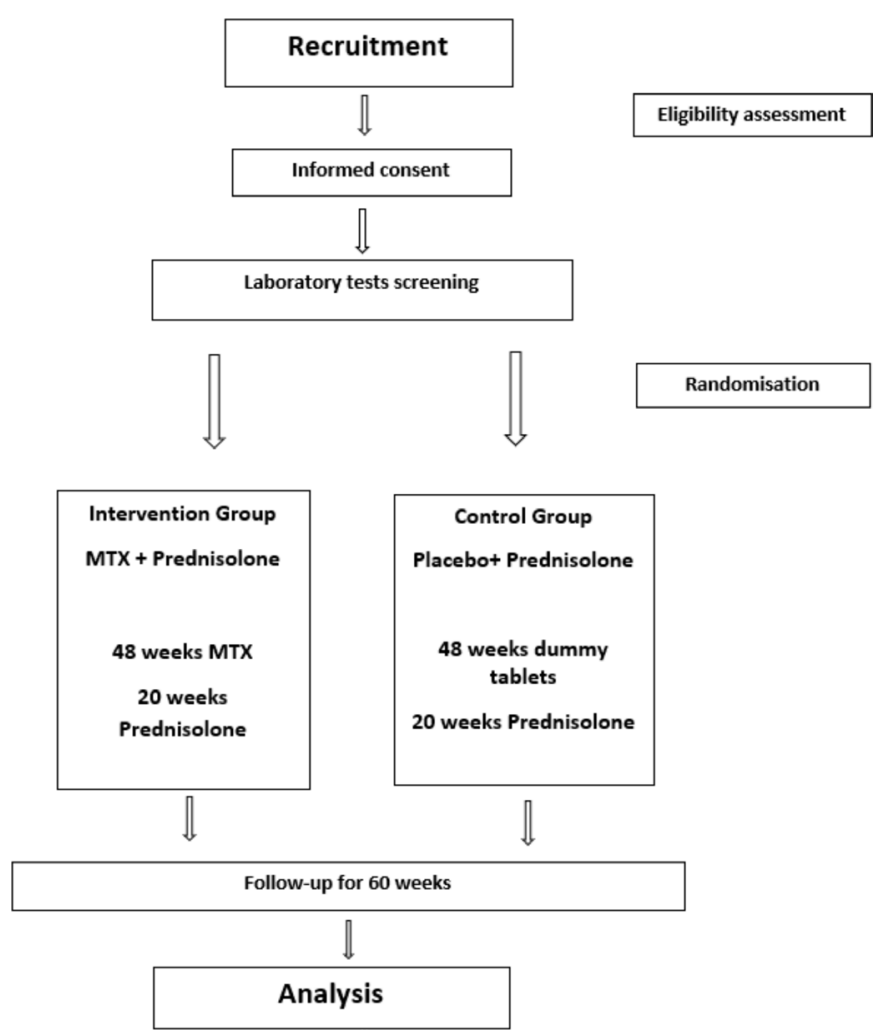

Figure 1 Overview of methotrexateand prednisolone study in erythema nodosum leprosum randomised controlled trial. MTX,methotrexate. 
Table 1 Treatment schedule for MaPs in ENL.

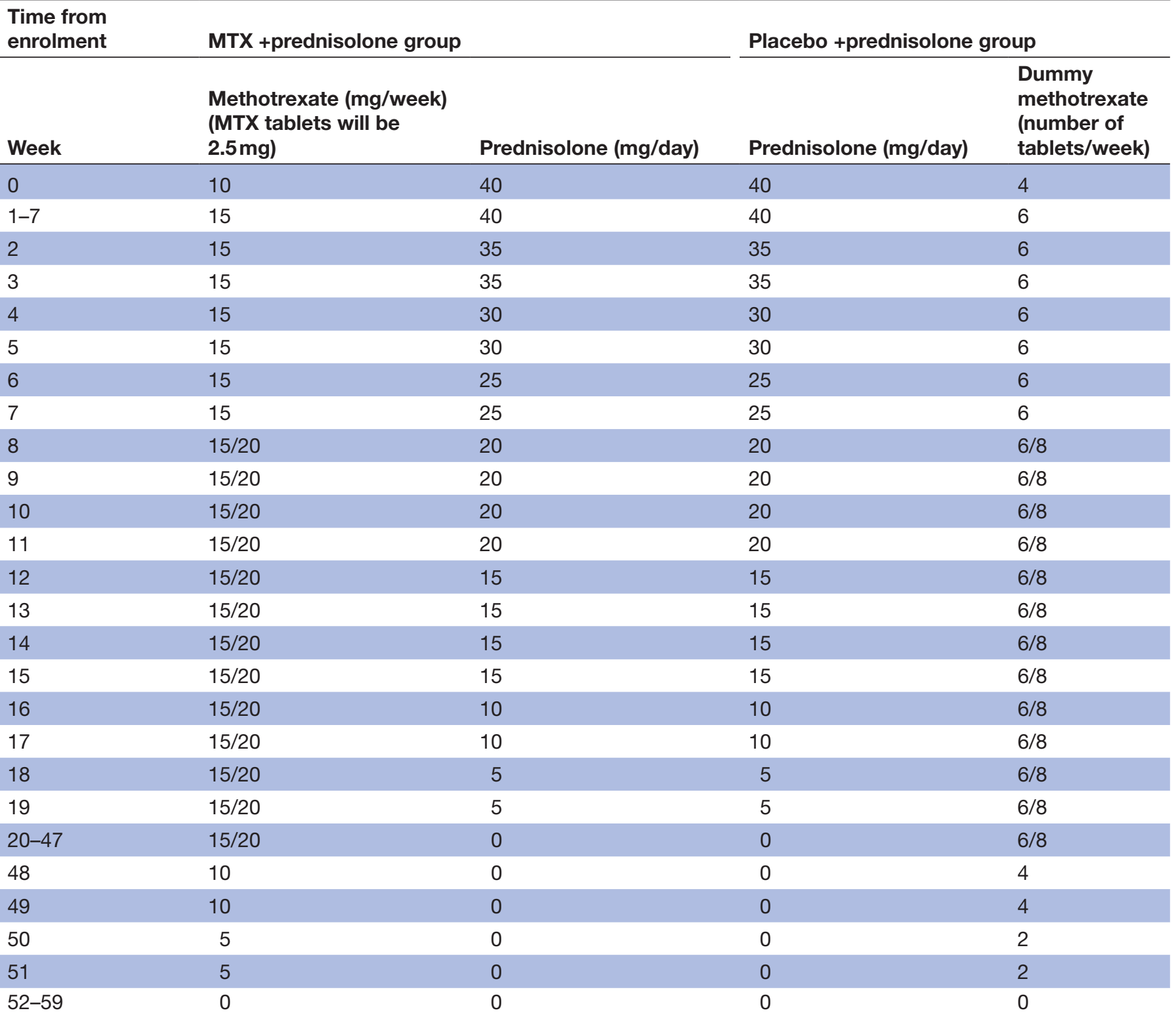

Participants weighing less than $60 \mathrm{~kg}$ will continue to receive $15 \mathrm{mg}$ of MTX weekly and individuals weighing $60 \mathrm{~kg}$ or more will receive MTX $20 \mathrm{mg}$ from week 8.

ENL, erythema nodosum leprosum; MaPs, methotrexate and prednisolone study; MTX, methotrexate.

than $60 \mathrm{~kg}$ will continue to receive $15 \mathrm{mg}$ of MTX weekly thereafter. Individuals weighing more than $60 \mathrm{~kg}$ will have the weekly dose of MTX increased to $20 \mathrm{mg}$ from week 8.

At week 48, the MTX will be reduced to $10 \mathrm{mg}$ for 2 weeks followed by $5 \mathrm{mg}$ for 2 weeks and then stopped.

In the control arm, participants will receive an equivalent number of identical dummy tablets.

All trial participants will receive prednisolone for 20 weeks. The initial dose will be $40 \mathrm{mg} /$ day, reducing to 0 . The study medications received by participants are detailed in table 1 .

\section{Medication}

All participants will be prescribed folic acid $5 \mathrm{mg}$ /day to minimise MTX-related adverse effects. ${ }^{24}$

\section{Adverse event}

All participants will be assessed for the occurrence of AEs of MTX and/or prednisolone using detailed clinical assessments and laboratory parameters. ${ }^{33}$

Nausea is a common AE of MTX, which may be severe enough to limit therapy and may lead to loss of concealment of group allocation in the study. Up to $35 \%$ of patients treated with MTX may experience nausea. ${ }^{34}$ Folate supplementation can reduce nausea and prevent anaemia and it is recommended for patients taking MTX. ${ }^{24} 3536$ Gastrointestinal (GI) AEs associated with corticosteroids are common in ENL trials. In a study in Ethiopia of 33 participants with ENL, 57\% reported GI AEs. ${ }^{20}$ An Indian RCT reported $43 \%$ of participants 
experienced GI AEs. ${ }^{18}$ ENL is a chronic condition, therefore many study trial participants have a long history of corticosteroid use. However, even in treatment of individuals newly diagnosed with leprosy reactions, GI AEs are common. In a nerve function impairment (NFI) prophylaxis study, almost $20 \%$ of participants who received prednisolone experienced GI symptoms. ${ }^{37}$

In the event of a serious $\mathrm{AE}$, the allocation will be unmasked and an individualised treatment scheme initiated. In the event of a minor AE, additional medication will be prescribed according to the standard of care, but allocation will not be unmasked.

\section{Indications for additional corticosteroids}

The indications for additional prednisolone are defined in the protocol as:

1. Flare or deterioration in ENL characterised by ENL symptoms and/or signs resulting in an increased EESS score to 9 or more; an increase in EESS score of 5 or more; orchitis not responding to conservative management and iritis not responding to topical steroids/ mydriatics.

2. New or a deterioration in nerve function impairment (NFI) characterised by motor impairment or sensory impairment.

3. Type 1 leprosy reaction.

Any participant needing additional prednisolone will receive a reducing course of prednisolone as per protocol (see online supplemental appendix 1, page 33).

\section{Monitoring}

During the study period, the study manager will monitor data collection. Meetings to update the progress of the study and identify any issue will be scheduled according to each centre's needs and if necessary further training can be provided to address problems arising. Regular online meetings will be conducted with all centres to discuss issues and updates.

\section{Data safety monitoring board}

A data safety monitoring board (DSMB) has been established with independent researchers with access to unblinded data to review the accruing data, to monitor the progress of the study, to assess whether there are any safety issues and to advise the sponsor whether to continue, modify or stop the trial. The DAMOCLES (DAta MOnitoring Committees: Lessons, Ethics, $\underline{\text { Statis- }}$ tics) charter was used as the model for organisation of the DSMB. ${ }^{38}$

\section{Data collection}

Data will be collected and managed using REDCap electronic data capture tools hosted at London School of Hygiene \& Tropical Medicine. ${ }^{39}$ REDCap is a secure, webbased application designed to support data capture for research studies providing audit trails for tracking data manipulation and export procedures; automated export procedures for seamless data downloads to common statistical packages and procedures for importing data from external sources. Identifiable data will not be exported to the database but will be kept at each centre.

\section{Data analysis}

The primary objective of the statistical analyses is to evaluate the efficacy and safety of MTX in the treatment of adult participants with acute and chronic/recurrent ENL. The efficacy analysis will be conducted in the intent-totreat population, safety analysis will be conducted in the safety population. The analyses for the primary outcomes for both parts of the trial each require a straightforward comparison of percentages. In addition, we will carry out last observation carry-forward (LOCF) analyses. This will mean that all subjects who are randomised will be analysed. However, we are aware of the limitations of the LOCF approach and will also apply the likelihoodbased method of mixed-effect model repeated measures (MMRM) ${ }^{40}$ We will also complete per protocol analyses. For secondary outcomes, LOCF and MMRM analyses will be applied.

Data and all appropriate documentation will be stored for a minimum of 5 years after the completion of the study, including the follow-up period.

\section{Patient and public involvement}

Individuals affected by ENL were consulted about the need for improved treatments and willingness to participate in clinical studies.

\section{Ethics and dissemination}

Ethical approval was obtained from the Observational/ Interventions Research Ethics Committee of the London School of Hygiene \& Tropical Medicine (15762); The Leprosy Mission International Bangladesh Institutional Research Board (in process); AHRI-ALERT Ethical Review Committee; Ethics Committee of the Managing Committee of the Bombay Leprosy Project; Health Research Ethics Committee Dr. Soetomo; The Leprosy Mission Trust India Ethics Committee; the Nepal Health and Research Council.

This study is registered at www.clinicaltrials.gov. Results will be submitted for publication in peer-reviewed journals and conclusions from the work will be presented at each participating centre and shared with study participants and other stakeholders. This article is based on the third version of the study protocol reviewed on 20 November 2018 (online supplemental appendix 1).

\section{DISCUSSION}

MaPs is a multicentre double-blind RCT, which aims to assess the efficacy of oral MTX in ENL. Corticosteroids are the most widely used drugs for the management of ENL. The use of prednisolone and other corticosteroids leads to severe complications such as infections, peptic ulcer, osteoporosis, glaucoma, diabetes and hypertension. Long-term use of these medications is associated with morbidity and mortality. Moreover, many patients 
suffer recurrent ENL when the dose of prednisolone is reduced. ${ }^{1}$ MTX has been used successfully in patients unresponsive to thalidomide and corticosteroids, making it an ideal candidate as a corticosteroid-sparing agent.

MaPs in ENL will be the first randomised clinical trial evaluating MTX as an option for ENL treatment. It will be the first ENL RCT to use the EESS tool to assess the severity and response to treatment, which will represent a major development in evidence-based therapeutics for ENL. We have developed criteria to standardise the prescribing of additional corticosteroids that could be used in other clinical trials of ENL.

MaPs in ENL will contribute to the evidence for the treatment of ENL and improve clinical trial methodology in leprosy reactions. Importantly, MaPs in ENL will use patients' reported outcome measures, which are valuable tools to assess outcomes. MTX if efficacious and safe will be an affordable and accessible medication with the potential to improve outcomes for individuals with this severe complication of leprosy.

\section{Author affiliations}

${ }^{1}$ Clinical Research Department, London School of Hygiene \& Tropical Medicine, London, UK

${ }^{2}$ Clinical Research Department, ALERT Center, Addis Ababa, London, Ethiopia

${ }^{3}$ Department of Dermatology and Mycobacterial Research Laboratories, The Leprosy Mission Nepal, Anandaban Hospital, Kathmandu, Nepal

${ }^{4}$ Bombay Leprosy Project, Mumbai, India

${ }^{5}$ The Leprosy Mission Trust India, New Delhi, Indonesia

${ }^{6}$ DBLM Hospital, The Leprosy Mission International Bangladesh, Nilphamari,

Bangladesh

${ }^{7}$ Department of Dermatology and Venereology, Faculty of Medicine Universitas Airlangga, Dr Soetomo General Hospital, Surabaya, Jawa Timur, Indonesia

${ }^{8}$ Leprosy Laboratory, Instituto Oswaldo Cruz, Rio de Janeiro, RJ, Brazil

Contributors Conceptualisation: SLW, DL. Data curation: PGN. Formal analysis: BdB, SLW, PGN. Study manager: BdB. Funding acquisition: SLW, DL. Investigation: MDA, CRB, JD, BdB, SD, DAH, SML, DL, NM, JACN, KDN, PGN, VVP, BJR, AMS, MS DS, SLW, AMY, VLAD. Methodology: MDA, CRB, JD, BdB, SD, DAH, SML, MYL, DL, JACN, KDN, PGN, WVP, BJR, AS, MS, DS, SLW, AMY. Project administration: MDA, CRB, JD, BdB, SD, DAH, SML, DL, NM, JACN, KDN, PGN, WVP, BJR, AS, MS, DS, SLW. Writing - original draft: BdB, SLW Writing - review \& editing: MDA, CRB, JD, SD, DAH, SML, DL, NM, JACN, KDN, PGN, VVP, BJR, AS, MS, DS, SLW.

Funding This work is supported by Leprosy Research Initiative, Turing Foundation and plan:g under LRI grant number 704.16.71 and The Hospital and Homes of St. Giles, grant number ITCRZM25.

Competing interests None declared.

Patient consent for publication Not required.

Provenance and peer review Not commissioned; externally peer reviewed.

Supplemental material This content has been supplied by the author(s). It has not been vetted by BMJ Publishing Group Limited (BMJ) and may not have been peer-reviewed. Any opinions or recommendations discussed are solely those of the author(s) and are not endorsed by BMJ. BMJ disclaims all liability and responsibility arising from any reliance placed on the content. Where the content includes any translated material, BMJ does not warrant the accuracy and reliability of the translations (including but not limited to local regulations, clinical guidelines, terminology, drug names and drug dosages), and is not responsible for any error and/or omissions arising from translation and adaptation or otherwise.

Open access This is an open access article distributed in accordance with the Creative Commons Attribution Non Commercial (CC BY-NC 4.0) license, which permits others to distribute, remix, adapt, build upon this work non-commercially, and license their derivative works on different terms, provided the original work is properly cited, appropriate credit is given, any changes made indicated, and the use is non-commercial. See: http://creativecommons.org/licenses/by-nc/4.0/.

\section{ORCID iDs}

Barbara de Barros http://orcid.org/0000-0002-5382-8165

Saba M Lambert http://orcid.org/0000-0003-4376-5495

Stephen L Walker http://orcid.org/0000-0002-2034-8376

\section{REFERENCES}

1 Pocaterra L, Jain S, Reddy R, et al. Clinical course of erythema nodosum leprosum: an 11-year cohort study in Hyderabad, India. Am J Trop Med Hyg 2006;74:868-79.

2 Kumar B, Dogra S, Kaur I. Epidemiological characteristics of leprosy reactions: 15 years experience from North India. Int $J$ Lepr Other Mycobact Dis 2004;72:125.

3 Walker SL, Lebas E, Doni SN, et al. The mortality associated with erythema nodosum leprosum in Ethiopia: a retrospective hospitalbased study. PLoS Negl Trop Dis 2014;8:e2690.

4 Walker SL, Balagon M, Darlong J, et al. ENLIST 1: an international multi-centre cross-sectional study of the clinical features of erythema nodosum leprosum. PLoS Negl Trop Dis 2015;9:e0004065.

5 Chandler DJ, Hansen KS, Mahato B, et al. Household costs of leprosy reactions (ENL) in rural India. PLoS Negl Trop Dis 2015;9:e0003431-13.

6 Job CK, Ebenezer GJ, Thompson K, et al. Pathology of eye in leprosy. In: Indian Journal of Leprosy. Vol 1998;70:79-91.

7 Polycarpou A, Walker SL, Lockwood DNJ. A systematic review of immunological studies of erythema nodosum leprosum. Front Immunol 2017;8:233

8 Moraes MO, Sarno EN, Almeida AS, et al. Cytokine mRNA expression in leprosy: a possible role for interferon-gamma and interleukin-12 in reactions (Rr and ENL). Scand J Immunol 1999;50:541-9.

9 Narayanan RB, Laal S, Sharma AK, et al. Differences in predominant $T$ cell phenotypes and distribution pattern in reactional lesions of tuberculoid and lepromatous leprosy. Clin Exp Immunol 1984;55:623-8 http://www.pubmedcentral.nih.gov/articlerender.fcgi? artid=1535912\&tool=pmcentrez\&rendertype=abstract

10 Sarno EN, Grau GE, Vieira LM, et al. Serum levels of tumour necrosis factor-alpha and interleukin-1 beta during leprosy reactional states. Clin Exp Immunol 1991;84:103-8.

11 Walker SL, Waters MFR, Lockwood DNJ. The role of thalidomide in the management of erythema nodosum leprosum. Lepr Rev 2007;78:197-215 http://www.ncbi.nlm.nih.gov/pubmed/18035771

12 Nabarro LEB, Aggarwal D, Armstrong M, et al. The use of steroids and thalidomide in the management of erythema nodosum leprosum; 17 years at the hospital for tropical diseases, London. Lepr Rev 2016;87:221-31.

13 Mahmoud M, Walker SL. A systematic review of adverse drug reactions associated with thalidomide in the treatment of erythema nodosum leprosum. Lepr Rev 2019;90:142-60.

14 Van Veen NHJ, Lockwood DNJ, Van Brakel WH, et al. Interventions for erythema nodosum leprosum. A cochrane review. Lepr Rev 2009;80:355-72.

15 Girdhar A, Chakma JK, Girdhar BK. Pulsed corticosteroid therapy in patients with chronic recurrent ENL: a pilot study. Indian $\mathrm{J}$ Lepr 2002;74:233-6.

16 Villahermosa LG, Fajardo TT, Abalos RM, et al. A randomized, double-blind, double-dummy, controlled dose comparison of thalidomide for treatment of erythema nodosum leprosum. Am J Trop Med Hyg 2005;72:518-26.

17 Sales AM, de Matos HJ, Nery JAC, et al. Double-Blind trial of the efficacy of pentoxifylline vs thalidomide for the treatment of type II reaction in leprosy. Braz J Med Biol Res 2007;40:243-8.

18 Kaur I, Dogra S, Narang T, et al. Comparative efficacy of thalidomide and prednisolone in the treatment of moderate to severe erythema nodosum leprosum: a randomized study. Australas J Dermatol 2009;50:181-5.

19 Roy K, Sil A, Das NK, et al. Effectiveness and safety of clofazimine and pentoxifylline in type 2 lepra reaction: a double-blind, randomized, controlled study. Int J Dermatol 2015;54:1325-32.

20 Lambert SM, Nigusse SD, Alembo DT, et al. Comparison of efficacy and safety of ciclosporin to prednisolone in the treatment of erythema nodosum leprosum: two randomised, double blind, controlled pilot studies in Ethiopia. PLoS Negl Trop Dis 2016;10:e0004149.

21 Kar HK, Gupta L. Comparative efficacy of four treatment regimens in type 2 leprosy reactions (prednisolone alone, thalidomide alone, 
prednisolone plus thalidomide and prednisolone plus clofazimine). Indian J Lepr 2016;88:29-38.

22 Maghanoy A, Balagon M, Saunderson P, et al. A prospective randomised, double-blind, placebo controlled trial on the effect of extended clofazimine on erythema nodosum leprosum (ENL) in multibacillary (MB) leprosy. Lepr Rev 2017;88:208-16.

23 Swierkot J, Szechinski J. Methotrexate in rheumatoid arthritis. Pharmacol Reports 2006;58:473-92.

24 Warren RB, Weatherhead SC, Smith $\mathrm{CH}$, et al. British association of dermatologists' guidelines for the safe and effective prescribing of methotrexate for skin disease 2016. Br J Dermatol 2016;175:23-44.

25 Gubner R. Effect of "aminopterin" on epithelial tissues. A M A Arch Dermatology Syphilol 1951

26 Hashkes PJ, Becker ML, Cabral DA, et al. Methotrexate: new uses for an old drug. J Pediatr 2014:164:231-6.

27 WHO. World Health organization model list of essential medicines. Who/mvp/emp/iau 2019;6.

28 Bedoui Y, Guillot X, Sélambarom J, et al. Methotrexate an old drug with new tricks. Int J Mol Sci 2019;20. doi:10.3390/ijms20205023. [Epub ahead of print: 10 Oct 2019].

29 Hossain D, Delwar H. Using methotrexate to treat patients with ENL unresponsive to steroids and clofazimine: a report on 9 patients. Lepr Rev 2013:84:105-12.

30 Kar BR, Babu R. Methotrexate in resistant ENL. Int J Lepr Other Mycobact Dis 2004;72:480.

31 Rahul N, Sanjay KS, Singh S. Effectiveness of methotrexate in prednisolone and thalidomide resistant cases of type 2 lepra reaction: report on three cases. Lepr Rev 2015;86:379-82 http:// search.ebscohost.com/login.aspx?direct=true\&db=a9h\&AN= 112006561 \&lang=es\&site=ehost-live
32 Walker SL, Sales AM, Butlin CR, et al. A leprosy clinical severity scale for erythema nodosum leprosum: an international, multicentre validation study of the ENLIST ENL severity scale. PLoS Neg/ Trop Dis 2017;11:e0005716-14.

33 Edwards IR, Aronson JK. Adverse drug reactions: definitions, diagnosis, and management. Lancet 2000;356:1255-9.

34 Kingsley GH, Kowalczyk A, Taylor $\mathrm{H}$, et al. A randomized placebocontrolled trial of methotrexate in psoriatic arthritis. Rheumatology 2012;51:1368-77.

35 Lorenzi AR, Johnson AH, Gough A. Daily folate supplementation is adequate prophylaxis against methotrexate-induced nausea and vomiting and avoids the need for expensive anti-emetic prescription. Rheumatology 2000;39:812-3.

36 Duhra P. Treatment of gastrointestinal symptoms associated with methotrexate therapy for psoriasis. J Am Acad Dermatol 1993;28:466-9.

37 Smith WCS, Anderson AM, Withington SG, et al. Steroid prophylaxis for prevention of nerve function impairment in leprosy: randomised placebo controlled trial (TRIPOD 1). BMJ 2004;328:1459-62.

38 DAMOCLES Study Group, NHS Health Technology Assessment Programme. A proposed charter for clinical trial data monitoring committees: helping them to do their job well. Lancet 2005; $365: 711-22$

39 Harris PA, Taylor R, Thielke R, et al. Research electronic data capture (REDCap)--a metadata-driven methodology and workflow process for providing translational research informatics support. J Biomed Inform 2009;42:377-81.

40 Siddiqui O, Hung HMJ, O'Neill R. MMRM vs. LOCF: a comprehensive comparison based on simulation study and 25 NDA datasets. J Biopharm Stat 2009;19:227-46. 